\title{
Erratum to: Recommendations for fertility preservation in patients with lymphoma, leukemia, and breast cancer
}

\author{
ISFP Practice Committee $\cdot$ S. Samuel Kim • \\ Jacques Donnez • Pedro Barri • Antonio Pellicer • \\ Pasquale Patrizio - Zev Rosenwaks • Peter Nagy • \\ Tommaso Falcone $\cdot$ Claus Andersen • Outi Hovatta • \\ Hamish Wallace • Dror Meirow • Debra Gook • \\ Seok H. Kim • Chii-Ruey Tzeng • Shuetu Suzuki • \\ Bunpei Ishizuka $\cdot$ Marie-Madeleine Dolmans
}

Published online: 23 August 2012

(C) Springer Science+Business Media, LLC 2012

Erratum to: J Assist Reprod Genet (2012) 29:465-468

DOI 10.1007/s10815-012-9786-y

The online version of the original article can be found at http://dx.doi.org/ 10.1007/s10815-012-9786-y.

S. S. Kim $(\bowtie) \cdot$ ISFP Practice Committee

Department of OB/GYN, University of Kansas Medical Center,

3901 Rainbow Blvd.,

Kansas City, KS 66212, USA

e-mail: skim2@kumc.edu

J. Donnez $\cdot$ M.-M. Dolmans

Department of OB/GYN, Universite Catholique de Louvain,

Brussels, Belgium

P. Barri

Department of OB/GYN, Institut Universitari Dexeus,

Barcelona, Spain

\section{A. Pellicer}

Department of OB/GYN, Instituto Universitario IVI,

Valencia, Spain

P. Patrizio

Department of OB/GYN, Yale University,

New Haven, CT 06511, USA

Z. Rosenwaks

Department of OB/GYN, Weill Cornell Medical College,

New York, NY 10021, USA

P. Nagy

Reproductive Biology Associates,

Atlanta, GA 30342, USA

T. Falcone

Department of OB/GYN, Cleveland Clinic,

Cleveland, OH 44195, USA
The original version of this article unfortunately contained a mistake. Dr. C-R Tzeng's address was incorrect. Korea should be changed to Taiwan.

\section{Andersen}

Department of OB/GYN, Copenhagen University Hospital,

Copenhagen, Denmark

O. Hovatta

Department of OB/GYN, Karolinska Institutet,

Stockholm, Sweden

H. Wallace

Royal Hospital for Sick Children,

Edinburgh EH9 1LF, UK

D. Meirow

Department of OB/GYN, Sheba Medical Center,

Tel-Hashomer, Israel

D. Gook

Reproductive Service, Royal Women's Hospital,

Parkville, Victoria, Australia

S. H. Kim

Department of OB/GYN, Seoul National University,

Seoul, Korea

\section{C.-R. Tzeng}

Department of OB/GYN, Taipei Medical University Hospital,

Taipei, Taiwan

S. Suzuki

Tokyo, Japan

B. Ishizuka

Department of $\mathrm{OB} / \mathrm{GYN}$,

St. Marianna University School of Medicine,

Kawasaki, Kanagawa, Japan 